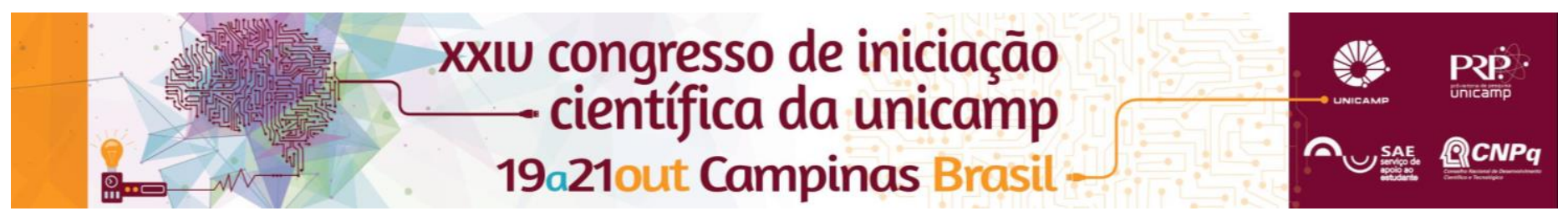

\title{
Potencial Evocado Auditivo de Tronco Cerebral em Lactentes Saudáveis que falharam na Triagem Auditiva
}

\author{
Jéssica L. P. Conceição*, Maria C. M. P. Lima
}

\section{Resumo}

A audição é importante na comunicação humana, desde o desenvolvimento intra-útero o ser humano percebe a presença do som e a partir desta habilidade poderá desenvolver as demais habilidades auditivas. Uma perda auditiva na criança pode causar atrasos no desenvolvimento da linguagem, educacional e social. Com a descoberta precoce da perda auditiva inicia-se a intervenção e busca-se amenizar as consequências que esta deficiência pode trazer à vida da criança e promover a qualidade de vida da mesma. Esse projeto teve como objetivo analisar os resultados dos testes audiológicos de neonatos saudáveis, de um hospital público, que falham na primeira etapa do programa de triagem auditiva neonatal. Foram avaliados neonatos que nasceram em boas condições de saúde, que falharam no teste da orelhinha e que compareceram para o Potencial Evocado Auditivo de Tronco Encefálico no período de Novembro de 2015 a Junho de 2016.

\section{Palavras-chave:}

neonato, diagnóstico, deficiência auditiva

\section{Introdução}

A deficiência auditiva infantil no Brasil, segundo o Censo 2010 do IBGE (Instituto Brasileiro de Geografia e Estatística $)^{1}$, apresenta uma prevalência de 1,5/1.000 nascidos vivos. A aquisição de linguagem nas crianças com deficiência auditiva não ocorre com mesma velocidade e no mesmo período de crianças ouvintes.

Em agosto $2010^{2}$, foi sancionada a Lei de $\mathrm{n}^{0}$ 12.303, que dispõe sobre a obrigatoriedade da realização de Emissões Otoacústicas (EOA) de forma gratuita nos hospitais e maternidades do país. Além das EOAs, nos casos de falha nas duas etapas da triagem auditiva, podese realizar o Potencial Evocado Auditivo de Tronco Encefálico (PEATE), um exame eletrofisiológico que mostra o funcionamento do sistema auditivo até a porção do tronco encefálico, sem a participação ativa do sujeito ${ }^{3-4}$.

O objetivo geral desta pesquisa foi analisar os resultados dos testes audiológicos de neonatos saudáveis, de um hospital público, que falham na primeira etapa do programa de triagem auditiva neonatal, no período de Novembro de 2015 a Junho de 2016.

\section{Resultados e Discussão}

Dos 1282 neonatos que realizaram a triagem auditiva, durante o período de análise, 106 (8,26\%) falharam no teste de Emissões Auditivas Evocadas (EOA); destes $32(30,18 \%)$ não voltaram ao serviço para nova triagem.

Dos 74 bebês que retornaram ao serviço, 7 $(9,45 \%)$ falharam novamente nas EOAs e foi realizado PEATE em 5 destes lactentes, um não compareceu e em um caso foi impossível a realização do exame.

Dos 106 casos que falharam no primeira etapa, 58 eram meninas e 48 meninos, sendo seis pré termos e 27 com Indicadores de alto risco para perda auditiva progressiva, sendo esses indicadores: medicação ototóxica, uso de bebidas alcoólicas e/ou drogas na gestação, histórico familiar, consanguinidade, infecções maternas e hiperbilirrubinemia.
Dos neonatos que realizaram PEATE, todos eram do sexo feminino, com indicadores de risco, sendo o mais presente o histórico familiar de Perda Auditiva.

Tabela 1. Triagem Auditiva Neonatal.

\begin{tabular}{|c|c|}
\hline DADOS & NÚMEROS \\
\hline $\begin{array}{c}\text { Total de Lactentes na } \\
\text { Triagem }\end{array}$ & 1282 \\
\hline Falharam na $1^{0}$ EOA & 106 \\
Não retornaram & 32 \\
\hline Falharam na $2^{0}$ EOA & 7 \\
Realizaram PEATE & 5 \\
\hline
\end{tabular}

\section{Conclusões}

Com os resultados obtidos nesta pesquisa foi possível identificar a baixa adesão das famílias no processo, com isso, muitos dos neonatos que falharam na triagem não fizeram a nova Triagem Auditiva, diminuindo o número de resultados

Por meio do PEATE, um dos lactentes, participantes da pesquisa, foi diagnosticado com Perda Auditiva bilateral. $\mathrm{O}$ neonato foi diagnosticado na idade em que é indicado pela Joint Comitte ${ }^{5}$ e a Lei Brasileira $12.303^{1}$.

\footnotetext{
${ }^{1}$ Instituto Brasileiro de Geografia e Estatística - IBGE. Resultados gerais da amostra do Censo Demográfico 2010. Rio de Janeiro: IBGE, 2012.

2 Durante AS.; Carvallo RMM.; Costa FS.; Soares JC. Características das emissões otoacústicas por transientes em programa de triagem auditiva neonatal. Pró-Fono Revista de Atualização Científica, 2005; 17(2): 133-140. 3 Sousa LCA.; Piza MRT.; Alvarenga KF.; Cóser PL. Eletrofisiologia da Audição e Emissões Otoacústicas: princípios e aplicações clínicas. $2^{\mathrm{a}}$ ed. Ribeirão Preto: Novo Conceito, 2010. p. 49-86.

${ }^{4}$ Vieira ABC.; Macedo LR.; Gonçalves DU. O diagnóstico da perda auditiva na infância. Pediatria (São Paulo) 2007; 29(1):43-49.

6Joint Committee on Infant Hearing. Year 2007 Position Statement: principles and guidelines for early hearing detection and intervention programs. Pediatrics. 2007; 120(4): 898-921.
} 